\title{
Correção de textos e concepções de língua e variação: relações nem sempre aparentes ${ }^{1}$
}

\author{
Maria Auxiliadora Bezerra \\ Anne Karine de Queiroz \\ Mariana Queiroga Tabosa \\ Universidade Federal de Campina Grande - UFCG
}

\begin{abstract}
Os objetivos deste trabalho são identificar conceitos de língua e de variação lingüística subjacentes à correção de textos escolares realizada por professores de língua materna e explicitar a relação entre esses conceitos e a correção/ avaliação feita. Para isso, foram analisadas duas redações corrigidas e avaliadas por um grupo de professores em formação continuada, tendo-lhe sido solicitada a justificativa para a nota a elas atribuída. A análise foi baseada em princípios teóricos relativos à formação de professor, correção/avaliação e concepções de linguagem. Os resultados indicam que os professores corrigem, sobretudo, seguindo normas do código, embora ao justificarem suas notas lancem mão de informações discursivo-textuais, demonstrando terem se apropriado de um discurso teórico moderno sobreposto a práticas tradicionais.
\end{abstract}

This paper has two main aims to be achieved. The first one relates to identifying concepts of language and linguistic variety subjacent to school texts correction led by teachers of mother tongue, whereas the second one concerns the elicitation of the relation between those concepts and the correction/evaluation practices adopted by the teachers. For that, two compositions were corrected and evaluated by a group of teachers to be. Afterwards, they were required to justify the grades given. The analysis was based on theoretical principles in relation to teacher training, correction/evaluation practices, and language concepts as well. The results show that although teachers correct compositions based mainly on code rules, during the grades justification phase they refer to discursive information. This implies that despite the fact that they have acquired a modern theoretical discourse, they still adopt traditional corretive practices.

${ }^{1}$ Esta análise faz parte da pesquisa Práticas de Escrita e de Reflexão sobre a Escrita em Contextos de Ensino, projeto integrado CNPq/UNICAMP/UFCG (proc.520427/2002-5 NV). 


\section{Introdução}

Tradicionalmente, compete ao professor de língua materna ensinar seus alunos a ler e escrever. Para isso, baseado em seus conhecimentos conteudísticos e didáticos, ele lhes propõe atividades diversificadas de leitura e escrita, que são corrigidas tendo em vista o parâmetro estabelecido: o "português correto". Esse quadro escolar, entretanto, passou a ser questionado, há duas décadas aproximadamente, considerando-se dois aspectos. O primeiro (cronologicamente) diz respeito ao conceito de "português correto", visto que, por influência das ciências da linguagem, a concepção de língua como um código homogêneo, cristalizado e neutro foi reconsiderada e, à luz de outros pontos de vista, passou a ser concebida como um conjunto de variações que se efetiva na interação entre sujeitos (logo, questiona-se a existência do "português correto", in abstracto). O segundo aspecto, que ganhou evidência a partir da última década, diz respeito à formação de professores, que ora enfatiza a homogeneidade da língua (Licenciaturas mais tradicionais), ora enfatiza estudos descritivos (Licenciaturas mais inovadoras). Em geral, porém, a formação de professores abarca conhecimentos desvinculados da experiência profissional, não possibilitando ao professor estabelecer uma relação entre o conhecimento teórico que recebe da universidade e sua prática cotidiana.

Considerando esse contexto e nosso trabalho com formação básica e continuada de professor, realizamos este estudo sobre correção e avaliação de textos escolares, efetivada por professores de língua materna, em situação de formação continuada (freqüentando um curso de especialização). Nossos objetivos são identificar conceitos de língua e variedade lingüística subjacentes a essa atividade didática e explicitar a relação existente entre esses conceitos e a correção/avaliação.

Nosso interesse em analisar essa atividade didática deve-se ao fato de ela constituir um trabalho docente constante, que deve refletir os princípios norteadores do projeto didático-pedagógico da escola e que, muitas vezes, não é objeto de estudo na formação dos professores.

\section{Procedimentos metodológicos}

Este estudo segue o paradigma interpretativista, podendo ser configurado como um estudo de caso, pois nossa atuação se restringiu 
a um grupo de 12 professores de Língua Portuguesa do ensino fundamental e médio, graduados em Letras por duas universidades públicas (uma estadual e outra federal) há no mínimo 01 ano e, no máximo, 12 anos, com experiência docente variando entre 01 e 14 anos, como está descrito do quadro 1 abaixo.

Quadro 1 - Descrição dos Professores

\begin{tabular}{|l|c|c|c|c|c|c|}
\hline $\begin{array}{c}\text { No de } \\
\text { Professores }\end{array}$ & $\begin{array}{c}\text { Faixa } \\
\text { Etária }\end{array}$ & $\begin{array}{c}\text { Curso de } \\
\text { Graduação }\end{array}$ & \multicolumn{2}{|c|}{$\begin{array}{c}\text { Universidade } \\
\text { de Origem }\end{array}$} & $\begin{array}{c}\text { Anos } \\
\text { Decorridos } \\
\text { após } \\
\text { Graduação }\end{array}$ & $\begin{array}{c}\text { Anos de } \\
\text { Experiência } \\
\text { Docente }\end{array}$ \\
\hline \multirow{2}{*}{12} & 25 a 40 & Letras & 07 & 05 & 01 a 12 & 01 a 14 \\
\cline { 4 - 5 }
\end{tabular}

Esses professores freqüentaram o Curso de Especialização em Lingüística Aplicada ao Ensino de Língua Portuguesa², com duração de 360 horas, oferecido pelo Departamento de Letras da Universidade Federal de Campina Grande, entre os meses de janeiro de 2002 e fevereiro de 2003, na cidade de Campina Grande (Paraíba).

A disciplina Análise e Preparação de Material Didático, a última do curso, teve como objetivos (1) avaliar material didático de língua portuguesa destinado ao ensino fundamental e médio, à luz das tendências da Lingüística Aplicada ao ensino de língua materna, e (2) preparar material para o ensino dessa língua, considerando a Lingüística e a Gramática. Como conteúdo específico foram estudados, entre outros, tópicos sobre concepções de linguagem, objetivos do ensino de língua portuguesa e avaliação de atividades e tarefas de ensino de leitura, escrita e gramática.

Entre o conjunto de atividades relativas a esse último ponto (avaliação de atividades e tarefas de ensino de leitura, escrita e gramática), foi realizada a correção de dois textos escritos por um mesmo aluno em séries diferentes ( $6^{\underline{a}}$ série do ensino fundamental e $1^{\underline{a}}$ série do ensino médio). A atividade de correção tinha como objetivo

\footnotetext{
2 Disciplinas do Curso: Tópicos de Sociolingüística ( 45 horas); Tópicos de Lingüística Textual ( 45 horas); Metodologia da Pesquisa Aplicada ao Ensino de Língua (60 horas); Metodologia do Ensino de Literatura (30 horas); Teoria e Prática de Leitura ( 45 horas); Teoria e Prática de Escrita ( 45 horas); Tópicos de Gramática (45 horas); e Análise e Preparação de Material Didático ( 45 horas).
} 
observar até que ponto as leituras e discussões efetivadas durante todo o curso de especialização, associadas às suas experiências, estariam influenciando os professores na tarefa de corrigir textos. Ou seja, que conceitos e procedimentos eles estariam mobilizando ao interferirem no texto do aluno. As principais leituras feitas pelos professores sobre correção/avaliação foram de Perrenoud (1999), Elizabeth Marcuschi (2001), Serafini (1989), Evangelista et al. (1998) e Ruiz (2001).

Aos professores foi solicitado o seguinte: Leia as redações abaixo, escritas por um aluno na $6^{\underline{a}}$ série do ensino fundamental e, depois, na $1^{a}$ do ensino médio, corrija-as e atribua-lhes uma nota. Diga e explique em que você está se baseando para fazer essa correção. A atividade foi realizada na própria sala de aula, durante aproximadamente uma hora, sem consulta aos textos teóricos lidos. Os textos do aluno (ver anexo) são uma notícia jornalística e um parágrafo narrativo-descritivo, escritos em situação de prova bimestral. Os seus resultados são justamente os dados de análise deste trabalho que ora apresentamos.

Abordaremos, a seguir, a formação de professor e a correção/ avaliação, com destaque para questões que se relacionam diretamente com nossos dados.

\section{Formação de professor}

A formação de professor, por influência da pedagogia tecnicista da década de 70 do século XX, se pauta, em geral, por princípios aplicacionistas, ou seja, ao professor em formação ou em serviço é ensinado que deve aplicar um determinado método de ensino, utilizar certas técnicas para garantir a aprendizagem dos alunos e o sucesso do ensino. Dessa forma, parte-se de alguns pressupostos, às vezes não conscientes: a língua é um código que funciona de maneira homogênea e independente dos interlocutores; a aprendizagem ocorre de forma passiva, sendo necessária apenas a imitação de modelos; e o ensino se dá pela exposição oral dos conteúdos de cada série aos alunos, que ao ouvirem/verem vão registrando as informações em sua memória.

O surgimento de outros pontos de vista, a partir dos anos 80-90, acerca da linguagem (cf. BAKHTIN, 1995), do processo ensinoaprendizagem (cf. VYGOTSKY, 1987) e das representações do mundo objetivo, social e subjetivo que se tem para interagir, entender, transformar os contextos onde se atua - o agir comunicativo (cf. 
HABERMAS, 1983), influenciando a formação de professores, vem provocar uma alteração no conceito de "formação de professor", que passa a ser entendido como a articulação de dois componentes curriculares: conhecimento teórico e conhecimento de ensino e de pesquisa sobre ensino (REINALDO, 2001).

A ênfase no conhecimento teórico vem desde a criação dos cursos de licenciatura (primeira metade do século XX), mas agora numa perspectiva diferente: procura-se dar ao futuro professor ou professor condições para que ele se posicione diante da pluralidade de estudos sobre a língua e reflita criticamente sobre fatos lingüísticos.

O conhecimento de ensino e de pesquisa sobre ensino, segundo Reinaldo (op. cit., p. 163), se dá pelas reflexões sobre o que vem a ser adquirir/aprender uma língua; sobre as capacidades e os fatores individuais ou coletivos (de ordem cognitiva, afetiva ou social) que interferem no processo de aprendizagem de uma língua; o papel do que se convencionou chamar de erro e das correções nesse processo evolutivo do aprendiz; e o efeito que determinados procedimentos de ensino formal, no tratamento de certas questões, podem provocar na aprendizagem e no desenvolvimento do educando.

Esse componente, ainda segundo a autora (op.cit.), leva o professor em formação e em serviço a uma reflexão crítica sobre seu próprio trabalho, devido ao desenvolvimento de uma atitude de pesquisa em relação à sua prática docente, que lhe possibilitará ver a sala de aula não como o lugar da certeza, ou de aplicação de um conhecimento acabado, mas como um espaço de busca do conhecimento. Trata-se do modelo de formação do professor chamado por Wallace (1991, apud MATTOS, 2002) de "modelo reflexivo", com duas dimensões principais: o conhecimento recebido, na forma de saber científico, e o conhecimento experiencial, relativo à experiência profissional. O primeiro se constitui de informações e teorias relacionadas a algum tipo de pesquisa e que são encontradas nos programas de formação; o segundo se constitui no saber tácito que o professor adquire como conseqüência natural de uma prática competente da profissão. Esse mesmo modelo, explicado de outra forma, é defendido por Tardif (2002), quando afirma que a crença na formação de professores, associada principalmente à sua atividade cognitiva ou intelectual, não demonstra resultados positivos se não forem considerados os saberes dos professores, produzidos socialmente. 
Nessa perspectiva é que analisamos as correções feitas pelos professores, tentando explicitar a associação entre conhecimentos conceituais e experienciais desses professores.

\section{Conceitos de correção e avaliação}

O embasamento teórico que fundamenta as práticas de correção/ avaliação dos professores será apresentado a seguir e utilizado, posteriormente, na análise dos dados.

\section{Correção}

Corrigir é intervir no texto do aluno, a fim de adequá-lo a normas lingüísticas e textual-discursivas. Trata-se de uma atividade complexa, que varia de acordo com o gênero textual, seu objetivo e seu escritor (sua formação e experiência), não sendo, portanto, capaz de proceder-se a essa atividade de forma mecânica, dentro de modelos pré-definidos.

Serafini (1989:108-112), em seus estudos sobre correção, expõe seis princípios que considera indispensáveis a essa prática: a) $a$ correção não deve ser ambígua (o que precisa ser mudado, na opinião do professor, deve estar bem especificado); b) os erros devem ser reagrupados e catalogados (uma forma de se proceder à classificação dos erros, especificando seu tipo); c) o aluno deve ser estimulado a rever as correções feitas, compreendê-las e trabalhar sobre elas (a concepção de que escrever é um processo contínuo que envolve reescrituras deve ser enfatizada entre os alunos); d) devem-se corrigir poucos erros em cada texto (evitar abordar muitos pontos que necessitam de reparos ao mesmo tempo, porque essa atitude pode desestimular o aluno-escritor); e) o professor deve estar predisposto a aceitar o texto do aluno (deve ter uma postura receptiva, sem preconceitos em relação ao tema, à linguagem, ao estilo etc. escolhidos pelo aluno); e f) a correção deve ser adequada à capacidade do aluno (apontar apenas pontos que o aluno tem maturidade para corrigir).

Esses princípios levam o professor a proceder de modos diferentes com o texto do aluno, resultando formas de corrigir diversas, que essa mesma autora (op. cit.) classifica como: a correção indicativa, na qual são marcados as palavras, as frases e os períodos que parecem pouco claros ao professor (ficando o aluno com a difícil tarefa de inferir o que 
errou); a resolutiva, que consiste em corrigir todos os erros, reescrevendo o que se considera incorreto (eliminação do erro pela solução que reflete a opinião do professor); e a classificatória, na qual se corrigem os "erros" classificando-os segundo seus tipos (se são de origem sintática, se dizem respeito à ortografia, à pontuação etc).

Complementando essa classificação, Ruiz (2001) propõe um quarto tipo de correção: a textual-interativa, intervenção realizada sempre nos espaços em branco (que não são nem o corpo, nem as margens do texto do aluno) do texto corrigido. São espécies de bilhetes ou cartas escritas pelo professor, ou para reforçar positivamente a tarefa realizada, ou para cobrar algo que não ficou claro durante a atividade. Esse quarto tipo de correção, segundo a autora, consegue preencher e/ou complementar as lacunas deixadas pelas outras formas de corrigir um texto, acima expostas, já que estabelece comunicação direta com o aluno-escritor, criando oportunidades de maior participação deste nas observações sobre seu texto. O que diferencia esta proposta de correção da anterior é o seu caráter especialmente interativo.

Outra posição relativa à correção de textos escolares vem-nos de Evangelista et al. (1998), segundo as quais há duas formas de se olhar, ou "reparar", o texto do aluno. A primeira, adotada por professores que vêem a língua como código, corresponde a uma perspectiva normativo/ prescritiva. Para eles, o conhecimento de regras gramaticais é indispensável ao desenvolvimento das habilidades de leitura e escrita. Conseqüentemente, o texto do aluno serve apenas como instrumento de verificação e aprendizagem de tópicos gramaticais. Porém não se estimula o aluno a ler o seu próprio texto e refletir sobre suas falhas. Daí a afirmação dessas autoras (op. cit.p.16) de que na tradição escolar, a avaliação tem se orientado pela busca de erros gramaticais.

A segunda forma, adotada por professores que vêem a linguagem como processo de interação, corresponde à perspectiva dialógica da língua. Para eles, o domínio da língua não depende exclusivamente do conhecimento de regras gramaticais, mas da relação dessas regras com as regras pragmáticas e discursivas envolvidas no processo de comunicação. Nesse caso, o primeiro passo para corrigir-se o texto do aluno é o estabelecimento de um "jogo interlocutivo", cuja prioridade é a busca do sentido do texto. Interessa, portanto, ao professor, observar a correspondência da produção do aluno com a proposta solicitada, o que o aluno tem a dizer e ainda de que estratégias ele se utiliza 
para dizer. O professor deve atentar, sobretudo, para a inter-relação forma, conteúdo e contexto.

Assim, durante sua prática pedagógica, o professor não privilegia um tipo específico de correção em detrimento de outro, visto que todos têm seu grau de importância e se complementam mutuamente. O que ele deve fazer é realizar sua correção de maneira clara, sem ambigüidade, para que o aluno possa realmente entender o que precisa ser melhorado em seu texto. Além disso, esse professor precisa ser o co-autor (Ruiz, op.cit.) do texto que corrige e não somente um observador que realiza apenas correções locais e superficiais, sem considerar o texto em seus aspectos temáticos e composicionais, pontos também essenciais.

\section{Avaliação}

Observando a avaliação de modo amplo, é válido afirmar que ela não é um fim em si mesma, mas um julgamento que aponta um caminho para o funcionamento didático. Assim, a avaliação não deve fazer parte apenas do jogo interlocutivo que se joga na escola, mas deve ter a força de renová-lo e reorientá-lo, deixando de ser uma atividade negativa para se tornar um momento privilegiado de se rever o processo ensino-aprendizagem (EVANGELISTA et al., op. cit., p. 16).

Corroborando as idéias acima, Perrenoud (1999) propõe a avaliação formativa em oposição à classificatória (ou normativa), cujo objetivo principal é hierarquizar as capacidades, tomando-se como base de sucesso ou de fracasso a nota conseguida pelo aluno. Nesta concepção, a avaliação é vista com um fim em si mesma, desvalorizando, por conseqüência, os conhecimentos e as competências dos alunos. Em oposição, a avaliação formativa enfoca a aprendizagem individual de cada aluno, ou seja, tem a preocupação de observar como andam as capacidades desse aluno, tornando-se, assim, uma estratégia pedagógica de luta contra ofracasso e as desigualdades (PERRENOUD, op. cit., p. 18) dentro da escola.

Lüdke \& Mediano (1992), em estudo realizado em escolas da zona sul do Rio de Janeiro, apontam a existência de dois tipos de avaliação. O primeiro é aquele que coloca o professor como o detentor do saber, transmissor único do conhecimento, e por isso toma o aluno como ser passivo do processo de aprendizagem; e o segundo, aquele que vê o professor como um mediador da aprendizagem do aluno, o qual passa 
a ser um agente ativo nesse processo (posturas idênticas às citadas por EVANGELISTA et al., op.cit.). Embora haja essas duas maneiras de se conceber a avaliação, em geral ela é (segundo as autoras) subjetiva e sem critérios bem definidos.

Serafini (op. cit., p. 130), afirma que a avaliação tem algumas funções que podem orientar o trabalho do professor: a função de mensuração, na qual um texto é avaliado em comparação a outros; a preditiva, que avalia o futuro desempenho do aluno; e a de pesquisa, que observa o progresso das capacidades do aluno em determinado espaço de tempo.

Para que essa prática seja bem-sucedida, a autora sugere que se levem em conta as diversas fases de desenvolvimento dos alunos; o objetivo dado ao texto no momento de sua produção, a fim de direcionar uma possível correção e avaliação do texto; o gênero utilizado, uma vez que as normas para a construção de um texto, em determinado gênero textual, podem influenciar o momento de sua avaliação; e o tipo de estímulo oferecido para se iniciar o processo da escrita, uma vez que a boa produção dependerá diretamente do embasamento dado pelo professor, influenciando na produção e, conseqüentemente, na avaliação.

Essa perspectiva é criticada por Evangelista et al. (op. cit.), ao afirmarem que reduzir a avaliação de textos a um conjunto de procedimentos a ser rigidamente seguido seria uma atitude simplista (p. 16). Assim, enquanto Serafini se propõe a estabelecer paradigmas de avaliação, Evangelista e outros (op. cit) defendem a idéia de que a avaliação pode se apresentar sob formas e momentos diversos. Nesta perspectiva, avaliar pode significar corrigir, reescrever, rascunhar, passar a limpo, confirmar ou negar hipóteses no ato da escrita, o que não precisa ser necessariamente realizado apenas na chamada "aula de redação" (p. 17).

Aqui o que cabe ao professor é ter conhecimento da avaliação como um ponto importante do processo de aprendizagem e não como o objetivo desse processo. Realizar um balanço das anotações coletadas durante a correção e esclarecer os critérios privilegiados são passos indispensáveis para uma prática coerente e que traz resultados. O aluno precisa entender o que foi feito no seu texto, para que ele possa passar à etapa seguinte e dar continuidade à sua aprendizagem. 


\section{Concepções de língua e variação lingüística}

Não é objetivo nosso, nesse tópico, apresentar o estado da arte em relação aos estudos desenvolvidos sobre concepções de linguagem, mas apenas retomar alguns conceitos mais difundidos que têm relação direta com a variação lingüística, pois esses pontos nos ajudaram a analisar nossos dados.

A tradição gramatical concebe a língua como uma abstração, uma essência, um ideal isolado, independente do povo que a fala. Isso se deve à influência da filosofia platoniana, que prega que as Formas só podem ser captadas pelo intelecto, não pelos sentidos. Sendo uma abstração, a língua não muda nem varia, e é vista como o ideal da perfeição a ser atingida. Essa concepção nos remete ao que se convencionou chamar de língua culta, que a escola deve ensinar, embora não se saiba exatamente qual é essa língua culta e se há alguém que a fale. Com esse objetivo e influência remota da filosofia platoniana, via compêndios gramaticais, a escola se especializa em ensinar as classes e categorias gramaticais para que o aluno se aproxime dessa abstração que é a língua.

Essa concepção de ensino de língua presente na maioria das escolas, reforçada pelo senso comum e pela mídia, é resultado de uma série de reduções - língua $=$ norma culta $=$ gramática da frase (BAGNO, 2002), que torna cada vez mais distante o falante real (aqui o aluno) dessa língua ideal.

Entretanto, se deslocarmos nosso olhar desse ideal para o real, saindo do abstrato para o concreto, veremos que a língua, como essência, não existe, o que existe são os sujeitos que a falam, imprimindo-lhe uma série de variações que são construídas numa realidade histórica, social e cultural. Ou seja, é uma atividade social, no dizer de Bagno (op. cit.), que se realiza sempre que os falantes interagem verbalmente. Dessa forma está sujeita às vicissitudes humanas, daí suas alterações, sua opacidade, suas variações.

Tomando emprestado afirmações encontradas em Marcuschi (2000, p. 20), citamo-las aqui para verificarmos como a concepção tradicional de língua é reducionista:

a) A língua apresenta uma organização interna sistemática que pode ser estudada cientificamente, mas ela não se reduz a um conjunto de regras de boa-formação que podem ser determinadas de uma vez 
por todas como se fosse possível fazer cálculos de previsão infalível. As línguas naturais são dificilmente formalizáveis.

b) A língua tem aspectos estáveis e instáveis, ou seja, ela é um sistema variável, indeterminado e não fixo. Portanto, a língua apresenta sistematicidade e variação a um só tempo.

c) A língua se determina por valores imanentes e transcendentes de modo que não pode ser estudada de forma autônoma, mas devese recorrer ao entorno e à situação nos mais variados contextos de uso. A língua é, pois, situada.

d) A língua constrói-se com símbolos convencionais, não aleatórios mas arbitrários. A língua não é um fenômeno natural nem pode ser reduzida à realidade neurofisiológica.

e) A língua não pode ser tida como um simples instrumento de representação do mundo como se dele fosse um espelho, pois ela é constitutiva da realidade. É muito mais um guia do que um espelho da realidade.

f) A língua é uma atividade de natureza sócio-cognitiva, histórica e situacionalmente desenvolvida para promover a interação humana.

g) A língua se dá e se manifesta em textos orais e escritos ordenados e estabilizados em gêneros textuais para uso em situações concretas.

h) A língua não é transparente, mas opaca, o que permite a variabilidade de interpretação nos textos e faz da compreensão um fenômeno especial na relação entre os seres humanos.

i) Linguagem, cultura, sociedade e experiência interagem de maneira intensa e variada, não se podendo postular uma visão universal para as línguas particulares.

Esse conjunto de informações contribui para reconhecermos que a língua é sistemática e variável, imanente e transcendente. Constróise com símbolos convencionais e arbitrários, não naturais. A língua não representa a realidade, mas é constitutiva dela, é de natureza sóciocognitiva, histórica e situacional, se manifesta em textos orais e escritos, estabilizados em gêneros textuais, permite variabilidade de interpretação, não podendo se prender a uma visão universal. Ou seja, uma língua particular não se deixa reduzir a uma só variedade, nem se define de forma apriorística, isolada de uma situação ou dos falantes. 
Nessa concepção de língua que promove a interação humana, as variações são características inerentes à própria língua: variação de espaço, de tempo, de grupo e individual. Em outras palavras, mudanças, variações e registros. Mudanças ao longo do tempo, do ponto de vista diacrônico; variações em uma mesma época, do ponto de vista sincrônico (variações geográficas e sociais); e registros, do ponto de vista do falante em relação à situação comunicativa (os vários registros que vão do mais informal ao mais formal).

\section{Intervenção dos professores nos textos do aluno}

Com base no referencial teórico exposto anteriormente, analisamos nossos dados, iniciando pela descrição das redações solicitadas. Os textos corrigidos foram escritos em situação de prova bimestral (como foi dito no item 2), momento em que se espera do aluno demonstrar seu conhecimento relativo aos tópicos estudados. O texto 1 foi redigido quando o aluno estava na $6^{\underline{a}}$ série do ensino fundamental de uma escola particular (em um bimestre cujo conteúdo incluía o estudo de textos jornalísticos) e atendia ao enunciado:

Redija uma pequena notícia com a seguinte manchete:

ALÔ VOCÊ: NOVAS ATRAÇÕES NO MAIOR CARNAVAL FORA DE ÉPOCA

Obs.: Lembre-se das três partes que compõem uma notícia. A manchete vocêjá tem, crie o lide e o corpo da notícia (minimo 6 linhas).

O texto 2 foi escrito quando o mesmo aluno estava na $1^{\text {a }}$ série do ensino médio de outra escola particular (em um bimestre cujo conteúdo era narração, descrição e dissertação) e atendia ao enunciado:

Mostre, num parágrafo narrativo-descritivo, as marcas de narração e as de descrição.

Nos dois enunciados, o que está sendo enfatizado é a estrutura e esperam-se textos curtos: o corpo da notícia com pelo menos 6 linhas e o texto 2 com um parágrafo. O comando para a escrita do texto 1, embora não apresente o termo gênero, na verdade traz subjacente a perspectiva teórica de gêneros, uma vez que está sendo solicitada a redação de uma notícia jornalística, mas a ênfase é apenas no seu componente composicional (manchete, lide e corpo da notícia); o texto 
2 enfatiza a tipologia clássica (narração, descrição, dissertação), especificamente o aspecto estrutural (marcas da narração e da descrição). Considerando essas informações no próprio enunciado da questão, percebemos que a correção/avaliação dos textos será orientada pelo atendimento total ou parcial de sua forma.

Verificando de que modo os professores corrigiram os textos, vemos que $24 \%$ deles reescreveram-nos, corrigindo suas falhas relativas ao conteúdo e à forma (correção resolutiva); 12\% apenas indicaram as falhas gramaticais (numa correção indicativa); e 64\% indicaram e classificaram os erros nos textos, seguindo a proposta de correção de Serafini (op.cit.). Desses 64\%, 25\% recorreram também à correção textual-interativa.

Exemplo 1

1.a) O bloco Alô você vai trazer para Campina Grande ... (indicativa) (texto 1 - prof.5)

1.b) A professora Lúcia dos Santos foi morta com 3 tiros em frente a sua casa ontem $=$ A professora Lúcia dos Santos foi morta ontem com 3 tiros, em frente a sua casa... (resolutiva) (texto 2 - prof.4)

1.c) Pontuação - você está introduzindo uma informação nova, que se refere ao surgimento do bloco, por isso deve usar um sinal de pontuação adequado. (textual-interativa) (texto 1 - prof.3)

Mais da metade dos professores (64\%) corrigiu os textos seguindo informações teóricas advindas das leituras realizadas no curso de especialização, ou seja, indicando e classificando os erros, o que significa uma postura de reflexão sobre o texto do aluno, com o intuito de orientá-lo a tomar outras decisões sobre seu texto, que difere de uma correção automática, com eliminação de todas as falhas, mas que não exige do aluno uma releitura de sua redação.

As notas atribuídas ao texto 1 variaram de 6,0 a 8,5 e ao texto 2 , de 7,5 a 10,0. Observando apenas essas notas, vemos que o texto 2 foi considerado melhor do que o texto 1 (a média das notas ficou em 7,3 e 8,5, respectivamente).Quando analisamos as justificativas para essas notas, vemos que há algumas incompatibilidades entre a linha argumentativa do professor e o peso dado às falhas apontadas.

Exemplo 2

2.a) Apesar das informações apresentadas sobre o que foi solicitado no enunciado da proposta da atividade, o texto contém algumas 
inadequações com relação ao aspecto formal (acentuação e pontuação) como também, não apresenta clareza e articulação de algumas idéias (...) Dessa forma, a nota $(6,0)$ atribuída ao texto, justifica-se pelas informações e pelo texto corresponder ao que foi solicitado, mas também a falta de coesão (...). (texto 1 - prof.3)

2.b) Analisamos no texto 2, que a aluna conseguiu construir o texto conforme a proposta apresentada. Houve um encadeamento das idéias, clareza nos fatos narrados. Por isso, a nota $(7,5)$ foi atribuída por esta aluna ter conseguido desenvolver o seu texto mostrando conteúdo de forma organizada. (texto 2 - prof.2)

Em 2.a, a primeira parte do texto (antes de ser atribuída a nota) levanos a crer que, por falhas gramaticais e falta de clareza e articulação de algumas idéias, a nota vai ser baixa. Na segunda parte, quando é dita a nota $(6,0)$, o professor justifica-a, argumentando que as informações sobre o tema foram dadas, que há adequação ao que foi solicitado (aspectos positivos), mas falta coesão (aspecto negativo). Assim, aparentemente, não fica claro para o leitor por que essa nota, mas considerando o conjunto do texto, deduz-se que o argumento prevalecente é o das falhas de forma.

Em 2.b, os argumentos apresentados (adequação ao solicitado, encadeamento de idéias, clareza nos fatos narrados e conteúdo apresentado de forma organizada) nos levam a crer que a nota será alta, mas é 7,5, a mais baixa atribuída a esse texto. Não foi indicada nenhuma falha para tal nota, embora no próprio texto do aluno haja correções indicativas e resolutivas para itens do código lingüístico.

Interpretamos esse procedimento como resultante de conhecimentos conceituais a que os professores tiveram acesso (coesão, coerência, adequação entre o solicitado e o realizado...) e suas experiências docentes, marcadas pela tradição (ênfase na gramática da palavra/frase). Isso faz o peso das falhas gramaticais ser maior e, conseqüentemente, a nota baixar.

Do conjunto dos professores, apenas um - o que havia concluído o curso mais recentemente e com menos tempo de experiência de ensino (um ano) - propõe a reescrita do texto, para em seguida ser dada a nota. Ou seja, o trabalho de correção é visto como uma interlocução com o aluno, orientando-o a refazer o texto, para adequá-lo ao gênero, ao tema e à forma. 
Exemplo 3

O comentário escrito no final do texto solicita ao aluno a rever sua produção, observando os apontamentos efetuados pela professora para posterior reescrita do texto. (...) Quanto à atribuição da nota será efetuada na última versão, segundo alguns autores a atribuição de notas na primeira versão pode comprometer um trabalho de releitura, revisão e reescrita do texto proposto. (textos 1 e 2 - prof.7)

Embora tenha sido bastante discutida no Curso de Especialização a necessidade de dar ao aluno a oportunidade de reescrever seus textos para adequá-lo ao solicitado e se apropriar de modelos de escrita compatíveis com os gêneros textuais, o professor do exemplo 3 não levou em conta que esse texto foi escrito numa situação de prova, sem oportunidade de uma refacção. Talvez, pelo pouco tempo de experiência docente e pelo fato de trabalhar em uma escola pública com cultura diferente daquela de escola particular (por exemplo, maior flexibilidade para que o professor possa escolher sua metodologia), o professor não considerou a cultura da escola particular (por exemplo, a entrega das notas, poucos dias após a aplicação da prova). Esses são saberes docentes que vão sendo construídos com a experiência cotidiana.

\section{Concepção de língua e variação lingüística subjacente à correção}

Comparando o tempo de experiência docente com a correção feita, observamos que os professores mais antigos são os que corrigem o texto considerando-o um produto acabado: o aluno faz sua versão e o professor a corrige, reformulando todas as partes que forem necessárias, segundo seu entendimento.

Exemplo 4

Corrigi principalmente o aspecto semântico. No lide especificando os elementos da notícia e no corpo estruturando as frases de forma a evitar o truncamento de idéias que dificultou a compreensão, principalmente do $2^{\circ}$ parágrafo. (prof. 1 - texto 1 )

Após esse comentário, segue-se o texto refeito e sem nota. Ou seja, o professor, lançando mão de uma correção resolutiva, demonstra entender a língua como um conjunto de regras que o aluno aprenderá 
se for observá-las. Assim, a língua é transparente e pode ser estudada de forma autônoma, independente de contextos de uso. O professor refaz o texto do aluno, ele o lê e "aprende" como escrever melhor, sem nenhuma negociação ou comentário entre professor e aluno.

As observações feitas nos textos do aluno e, em seguida, a explicação para a nota dada levam-nos a perceber que a maioria dos professores (88\%) concebe a língua (pelo menos nesses dados) como a tradição gramatical: conjunto de regras e classificações abstratas a serem aprendidas para uso posterior. A idéia de língua como atividade social, de que fala Bagno (op. cit.), através da qual os falantes interagem, parece não ser defendida por eles e as variedades lingüísticas que vão sendo utilizadas conforme as situações não são consideradas pelos professores.

Exemplo 5

O texto $\mathrm{n}^{\mathrm{o}} 1$ apresenta, no primeiro parágrafo, o nome da cidade onde ocorrerá o evento, o nome do bloco, atrações, o local de concentração, o lugar onde termina a festa e ressalta que as pessoas vão se divertir. Há a necessidade de acentuar a palavra "várias", faltou destacar o $2^{\circ}$ nome do bloco em inicial maiúscula "Alô Você". O dia da semana, "quinta-feira" deve estar escrito em inicial minúscula porque é substantivo simples. (texto 1 - prof.4)

Ao enfatizar, apenas, esses elementos de ordem microestrutural do código (acentuação, letra maiúscula e minúscula), o professor despreza outros aspectos do texto que têm relação direta com a situação de comunicação: trata-se do gênero notícia jornalística, que tem um objetivo comunicativo e que para ser escrito levam-se em conta aspectos temáticos, composicionais e estilo. E o texto em questão não apresenta apenas falhas de acentuação, ortografia, pontuação. Ele demonstra que o aluno não aprendeu a escrever o gênero notícia, mesmo em nível elementar (visto que não se trata de estudante de jornalismo).

Em relação à variação lingüística, o que se observa é que não há lugar para ela. Visto que os textos foram solicitados em contexto de exame e a tradição escolar se volta para a aprendizagem do registro formal, os professores os corrigiram sem fazer nenhuma alusão à variedade lingüística, mas apontando trocas de palavras ou expressões, consideradas como erro, para ajustar o texto ao modelo padrão. 


\section{Exemplo 6}

No texto $n^{\circ}$ 2, o aluno conseguiu relatar o fato, mas há problemas de repetição de palavras que podem ser substituídas por anafóricos, como está destacada na correção. Seria importante a presença do advérbio "ontem" no início do texto porque contextualiza, mais rapidamente, a data do acontecimento. Sugeri uma substituição ou modificação da frase: "para ir para casa e ela sempre vai a pé" por "e voltava para casa a pé, como sempre fazia" para que a notícia ficasse mais coerente. (texto 2 - prof. 4)

As intervenções do professor, no exemplo 6, vão na direção de tornar o texto mais formal (para ir para casa e ela sempre vai a pé por e voltava para casa a pé, como sempre fazia), apesar de ele ter escrito ficar mais coerente, o que remete ao sentido e não ao registro. Esse procedimento pode ser interpretado como a explicitação de que o professor se apropriou de princípios teóricos sobre texto (coerência, anáfora e outros), mas não os mobilizou de forma adequada, ao corrigir os textos, não fazendo distinção entre critério de textualidade (coerência) e variação lingüística (registro formal/informal).

\section{Considerações Finais}

Os dados analisados permitem-nos inferir que a atividade de corrigir e avaliar textos de alunos se pauta principalmente pelo caminho da tradição, que considera a língua uma abstração, um conjunto de regras a serem seguidas. Com isso, corrigir/avaliar textos é muito mais apontar erros do código, ou corrigi-los, do que considerá-los como uma forma complexa que precisa atender a vários pontos, desde as unidades menores (ortografia, acentuação) até, e principalmente, as unidades maiores, que envolvem o objetivo comunicativo, o gênero, a variedade lingüística, o destinatário, o veículo de divulgação. Dessa forma, a relação entre concepções de língua, variação e correção feita pelos professores não se apresenta de forma tão simples: teoricamente, eles demonstram ter uma concepção enunciativa de língua, mas ao realizar a correção, lançam mão de correntes prescritivas. 


\section{Referências Bibliográficas}

BAGNO, M. et al. Língua materna. São Paulo: Parábola, 2002.

BAKHTIN, M. Marxismo e filosofia da linguagem. 7. ed. São Paulo: Hucitec, 1995.

EVANGELISTA, A.A. M. e outros. Professor-leitor - aluno-autor: reflexões sobre avaliação do texto escolar. Cadernos CEALE, v. III, ano II, out. 1998.

HABERMAS, J. Conhecimento e interesse. São Paulo: Abril Cultural, 1983. (Coleção Os Pensadores).

LÜDKE, M. \& MEDIANO, L. (Coord.). Concepção de avaliação. In: Avaliação na escola de $1^{\circ}$ grau: uma análise sociológica. Campinas: Papirus, 1992. p. 107-114.

MARCUSCHI, L.A. Opapel da lingüística no ensino de lingua. Conferência proferida no $1^{\circ}$ Encontro de Estudos Lingüístico-Culturais da UFPE, dez. 2000. Disponível em: http://www.marcosbagno.com.br/conteudo/forum/ marcuschi.htm. Acesso em: 20 jul.2003.

MARCUSCHI, E. Os destinos da avaliação no manual do professor. In: DIONISIO, A.P.; BEZERRA, M. A. (Org.). O livro didático de português: múltiplos olhares. Rio de Janeiro: Lucerna, 2001. p.139-150.

MATTOS, A. M. de A. O professor no espelho: conscientização e mudança pela auto-observação. Revista brasileira de lingüistica aplicada, Belo Horizonte, v.2, n.1, p.121-155, 2002.

PERRENOUD, P. A avaliação entre duas lógicas. In: . Avaliação: da excelência à regulação das aprendizagens. Porto Alegre: Artes Médicas Sul, 1999. p. 9-23.

REINALDO, Ma. A.G.de M. Teoria e prática na formação do professor. Boletim da ABRALIN, Fortaleza, v.26, n. especial, I, p. 163-165, 2001.

RUIZ, Eliana. Como se corrige redação na escola. Campinas: Mercado das Letras, 2001, p.13-73.

SERAFINI, M. T. Como escrevertextos. Rio de Janeiro: Globo, 1989, p.107-145.

TARDIF, M. Saberes docentes e formação profissional. 2. ed. Petrópolis: Vozes, 2002.

VYGOTSKY, L. Pensamento e linguagem. São Paulo: Martins Fontes, 1987.

WALLACE, M. J. Training foreign language teachers: a reflective approach. Glasgow: Cambridge University Press, 1991. 


\section{Anexo}

Textos escritos pelo aluno, atendendo aos comandos:

1) Redija uma pequena notícia com a seguinte manchete:

ALÔ VOCÊ: NOVAS ATRAÇÕES NO MAIOR CARNAVAL FORA DE ÉPOCA

Obs.: Lembre-se das três partes que compõem uma notícia. A manchete você já tem, crie o lide e o corpo da notícia (mínimo 6 linhas).

O bloco Alô você vai trazer para Campina Grande varias atrações como a banda Araketo, Fernando Vanuci e muitas outras. Vai sair na Quinta-feira, começa no SPAZZIO e termina no PARQUE DO POVO onde a folia vai estar solta.

A precisam da prefeitura foi construir esse bloco pois muitas pessoas famosas vinheram para eles ficarem juntos construíram o bloco que ai o trouxeram o Arakato e fizeram o bloco que vocês vem

\section{ALÔ VOCÊ}

FIM

2) Mostre, num parágrafo narrativo-descritivo, as marcas de narração e as de descrição.

A professora Lúcia dos Santos foi morta com 3 tiros em frente a sua casa ontem na Rodrigues Alves às 7 horas da noite. Lúcia tinha saído da escola, onde dá aula, dois homens armados a abordaram e pediram sua bolsa. Lúcia não quis entregar e saiu correndo e gritando, para que lhe salvasse então os dois homens começaram a tirar e 3 tiros a acertaram-na dois nas costas e um na nuca e fugiram, e Lúcia morreu na hora. 